\title{
INTERACIONISMO SIMBÓLICO: ORIGENS, PRESSUPOSTOS E CONTRIBUIÇÕES AOS ESTUDOS ORGANIZACIONAIS
}

\author{
SYMBOLIC INTERACTIONISM: ORIGINS, ASSUMPTIONS AND
} CONTRIBUTIONS TO ORGANIZATIONAL STUDIES

\section{Virgínia Donizete de CARVALHo (vircah@gmail.com) UNIVERSIDADE FEDERAL DE ALFENAS}

\section{RESUMO}

O artigo apresenta uma revisão acerca da perspectiva interacionista simbólica, resgatando suas origens, pressupostos básicos e possibilidades de contribuição aos estudos organizacionais. São examinadas algumas concepções de precursores desta corrente, e abordados os marcos iniciais da estruturação do movimento interacionista simbólico, bem como as divergências conceituais e metodológicas das Escolas de Chicago e Iowa, além das principais críticas apresentadas a esta perspectiva teórica. Entende-se que o interacionismo simbólico apresenta um potencial para compreensão de diferentes aspectos da vida organizacional, complementando outras perspectivas teóricas normalmente utilizadas neste campo de estudos. Num esforço de exemplificar tal potencialidade, busca-se elucidar alguns temas em estudos organizacionais, que têm sido abordados sob a perspectiva interacionista simbólica, bem como tecer algumas considerações acerca dos aspectos metodológicos relacionados à operacionalização de seus pressupostos. Salienta-se, por fim, que para a utilização adequada de tal abordagem, os pesquisadores devem estar conscientes de suas limitações.

Palavras-chave: interacionismo simbólico; pressupostos teóricos; perspectivas metodológicas; estudos organizacionais. 


\section{ABSTRACT}

This paper presents a theoretical review of the symbolic interactionist perspective, revisiting its roots, consolidation, main assumptions and how it can contribute to the field of organizational studies. The concepts from some of acknowledged pioneers of this approach are examined and the initial landmarks heralding the consolidation of the symbolic interactionism movement are addressed. Furthermore, conceptual and methodological divergences between the Chicago and Iowa schools are discussed, as are the primary critiques of this theoretical perspective. It is assumed that symbolic interactionism represents a potential to understand different aspects of organizational life, complementing other theoretical perspectives generally used in this field of studies. To illustrate this potential, the paper cites a number of issues in organizational studies that have been addressed from the symbolic interactionist perspective, and comments on methodological aspects related to the accomplishment of its main assumptions. Finally, it emphasizes that researchers must be aware of the limitations of the interactionist approach in order to use it appropriately.

Keywords: symbolic interactionism; theoretical assumptions; methodological perspectives; organizational studies.

\section{INTRODUÇÃO}

As imagens, premissas e concepções que compõem uma perspectiva teórica dão direção à investigação científica. Por esta razão, o conhecimento das contribuições e limitações de dada perspectiva torna-se importante por revelar as possibilidades de aplicação mesma (MORGAN, 1983). Com base nessas considerações, o presente estudo se propõe a apresentar uma revisão acerca da perspectiva teórica denominada interacionismo simbólico, resgatando suas origens, pressupostos centrais e possibilidades de contribuição aos estudos organizacionais.

A perspectiva interacionista simbólica, que tem suas raízes na sociologia e na psicologia social, possibilita a compreensão do modo como os indivíduos interpretam os objetos e as outras pessoas com as quais interagem e como tal processo de interpretação conduz o comportamento individual em situações específicas. Autores como Kanter (1972) e Hall (1987) apontam a utilidade e importância do interacionismo simbólico no estudo da vida social, por apresentar uma percepção dos 
indivíduos como capazes de utilizar seu raciocínio e poder de simbolização para interpretar e adaptar-se flexivelmente às circunstâncias, dependendo do modo como venham a definir a situação.

Ao estudar o comportamento humano, considerando sua interação mediante comunicações simbólicas, em que os significados das ações podem ser mantidos, modificados ou dados pelos atores, cujo self atua como mediador entre estes e a organização social (BLANCO, 1988), o interacionismo simbólico representa um potencial para compreensão de diferentes aspectos da vida organizacional. Nesse sentido, complementa outras perspectivas teóricas normalmente utilizadas neste campo de estudos.

Conforme salienta Coulon (1995), o interacionismo simbólico trouxe às ciências sociais, um lugar teórico para o sujeito social como intérprete do mundo, pondo em prática, com isso, métodos de pesquisa que privilegiam o ponto de vista desses sujeitos. O objetivo do emprego dessas abordagens é elucidar as significações que os próprios sujeitos põem em prática para construir seu mundo social, o que torna o interacionismo simbólico uma perspectiva teórica especialmente adequada à condução de investigações qualitativas. Cumpre salientar, todavia, que seus pressupostos são também compatíveis com métodos quantitativos, favorecendo os desenhos de pesquisa que se caracterizem pela combinação de múltiplos métodos (BENZIES; ALLEN, 2001).

Diante do exposto, o presente estudo teórico discute o surgimento, a consolidação e os pressupostos centrais da perspectiva interacionista simbólica, revisando as concepções teóricas dos estudiosos que mais contribuíram para o seu desenvolvimento. Na sequência, busca identificar as contribuições e potencialidades de utilização desta perspectiva teórica nos estudos organizacionais, apresentando algumas reflexões finais acerca das principais vantagens de seu emprego no referido campo de estudos e salientando a importância de se reconhecer as suas limitações.

\section{RAÍZES TEÓRICAS E CONSOLIDAÇÃO DO INTERACIONISMO SIMBÓLICO}

Os problemas sociais decorrentes da industrialização e urbanização do início do século XX constituíram o contexto que serviu como uma das fontes de estímulo aos estudiosos da época para desenvolver uma perspectiva teórica distinta, voltada ao estudo sistemático do comportamento social humano. As contribuições teóricas que vieram dar origem a esta perspectiva, conhecida como interacionismo simbólico, são 
advindas das obras de clássicos da Escola de Chicago como Charles Cooley, John Dewey, William Thomas e, sobretudo, George Mead, considerado como o principal precursor e inspirador do movimento interacionista (HAGUETTE, 1995; JOAS, 1999; TREZZA, 2002; ÁLVARO et al., 2007).

Destaca-se a influência da filosofia do pragmatismo ${ }^{1}$ sobre os estudiosos da Escola de Chicago. Esta teve início com os trabalhos de Dewey e Mead, especialmente no que se refere à interpretação dos processos e operações psíquicas, segundo sua eficácia para a solução dos problemas encontrados pelas pessoas no curso de sua conduta. Nas palavras de Joas (1999), "Cooley foi o primeiro a proclamar a necessidade de um pragmatismo 'social' ou 'sociológico' e o primeiro a desenvolver uma teoria do eu e sua dependência de grupos primários" ( $\mathrm{p}$. 138). Entretanto, a solução do problema de se chegar a uma análise pragmática de situações de interação social e autorreflexão individual foi creditada a Mead, por ter focado a ação interpessoal, indicando que o modo de ação de um indivíduo suscita reações de seu parceiro, tornandose condição para a continuidade de suas próprias ações.

Sabendo-se que o pragmatismo foi um dos produtos das ideias evolucionistas britânicas (ÁLVARO; GARRIDO, 2003) e que Mead, no terreno filosófico, era um pragmatista (PORTUGAL, 2006), torna-se perceptível que, em alguns aspectos, as ideias de Darwin tiveram impacto sobre o pensamento de Mead. É observável também a atenção que dedicou às elaborações de Wundt e às concepções behavioristas. Entretanto, é fato inegável que em suas discussões sempre reconhecia as limitações de cada uma das correntes de pensamento citadas, apresentando críticas às mesmas. Assim, discutia a incapacidade do pragmatismo de explicar as origens do indivíduo como ser social; a explicação de Cooley sobre a natureza social do ser humano, baseada em processos subjetivos; a aceitação de Wundt em relação ao fenômeno da mente humana, sem se preocupar com sua emergência e a pretensão reducionista do behaviorismo de explicar o comportamento humano por meio do esquema E-R (Estímulo-Resposta) (BLANCO, 1988).

Mead (1934)reconhece que o ato possui tanto uma fase interna quanto externa. Para ele, a questão surge no modo como essas duas fases se relacionam. Portanto, critica Wundt por pressupor a mente em sua psicologia fisiológica, e Watson por abandoná-la em seu behaviorismo. Para Farr $(1998$, p. 80) "ambas as perspectivas são parciais e não há nada de inerentemente social em nenhuma delas. O que Mead fez foi mostrar como elas poderiam se relacionar". 
Estas considerações estão claras em sua obra, como é possível constatar neste trecho em que esclarece, em termos de behaviorismo, qual é o ângulo de seu enfoque:

$\mathrm{O}$ ato, e não o trajeto é o dado fundamental na psicologia social e na psicologia individual, quando são concebidas na forma condutista, e tem por sua vez uma fase interna e outra externa, um aspecto interior e outro exterior. (...) nosso ângulo de enfoque é condutista, mas diferentemente do condutismo watsoniano, reconhece as partes do ato que não aparecem na observação externa e acentua o ato do indivíduo humano em sua situação social natural (MEAD, 1934, p.55).

Conforme se observa, no entendimento de Mead (1934), a compreensão da conduta é incontestavelmente diferenciada de Watson. Ele argumenta detalhadamente em sua obra que certas partes do ato se convertem em um estímulo para que o outro indivíduo se adapte a tais reações; e essa adaptação se converte, por sua vez, em estímulo para que o primeiro modifique seu ato e inicie outro distinto.

Portanto, a descrição de Mead do comportamento humano tem como dado principal o ato social, em termos não só de comportamento externo observável, mas também de atividade encoberta do ato. Enquanto Watson reduz o comportamento humano aos mesmos mecanismos encontrados em nível infra-humano, em que a dimensão social é vista como uma mera influência externa sobre o indivíduo, insistindo no estudo estritamente científico do comportamento aparente; Mead permite uma instintiva investigação compreensiva de aspectos do comportamento, ausente na perspectiva de Watson (HAGUETTE, 1995).

Mead (1934) afirma que a mente é uma relação do organismo com a situação, que se realiza por meio de uma série de símbolos. Quando um determinado gesto representa a ideia que há por trás de si e provoca essa ideia no outro indivíduo, tem-se um símbolo significante. No momento em que tal gesto promove uma reação adequada do outro indivíduo, temse um símbolo que responde a um significado na experiência do primeiro indivíduo e que também evoca esse significado no segundo indivíduo.

Assim, a base da significação está presente na conduta social, em que emergem os símbolos significantes. Só quando o indivíduo se identifica com tais símbolos, se torna consciente a significação. Os processos mentais têm relação com esta significação das coisas e a mentalidade reside na capacidade do organismo para indicar aquele elemento do ambiente que responde às suas reações, a fim de poder 
controlar tais reações de várias maneiras. Nas palavras do próprio Mead (1934, p. 165), "o controle é possibilitado pela linguagem (...) e da linguagem emerge o campo da mente".

Conforme pontua Blanco (1988), o que Mead queria demonstrar era que a ação de cada um só obteria seu sentido por meio da ação do outro. Durante o processo de qualquer ato social, os objetos do ambiente percebido se definem e se redefinem. De tal dinamismo consiste a interação simbólica, a qual não se dá por reação direta às ações e gestos do outro, mas, mediante uma interpretação destas ações ou gestos com base no significado que lhes é atribuído.

Para explicar este processo de interação que envolve definição e redefinição de objetos do ambiente percebido, Mead introduz as noções de Self, Eu e Mim. A característica da pessoa como objeto para si está representada pelo termo Self (si mesmo), e este Self permite que o indivíduo interaja socialmente consigo mesmo, da mesma forma que ele interage socialmente em relação a outras pessoas. "Quando não só se escuta a si, mas também se responde [...] tão realmente como se responde a outra pessoa, então temos uma conduta em que os indivíduos se convertem em objetos para si mesmos" (MEAD, 1934, p. 171).

Esta capacidade de refletir sobre si mesmo, que também permite o processo de se perceber e/ou sentir-se no papel do outro, habilita o ser humano a desenvolver o sentido de Self social. De acordo com Jeon (2004), o Self precisa ser entendido de forma situada na interação com o mundo social. A pessoa e o mundo não podem ser compreendidos de forma isolada, porque o Self está sendo continuamente desenvolvido por meio da interação com outros seres humanos. Isto explica a natureza do Self, que é dinâmica e não fixa.

Portanto, a sociedade representa o contexto dentro do qual o Self surge e se desenvolve. Haguette (1995) esclarece que o Self representa um processo social no interior do indivíduo, que envolve duas fases analíticas distintas: o "Eu", que é a tendência impulsiva do indivíduo e o "Mim", que representa o outro generalizado. É na forma do outro generalizado (MEAD, 1934) que os processos sociais influenciam a conduta dos indivíduos envolvidos e a comunidade exerce controle sobre o comportamento dos seus membros individuais. Quando as pessoas ficam fora dessa classe de expressão organizada, surge uma situação em que o controle está ausente. A reação do indivíduo ao outro generalizado representa o $\mathrm{Eu}$ na experiência da pessoa. O pensamento seria o raciocínio do indivíduo, uma conversação entre o que se denomina de "Eu" e de "Mim". 
Nas palavras de Mead (1934, p. 222), é possível observar este papel do "Eu" e do "Mim" num processo de interação contínua.

O Mim é um indivíduo convencional, habitual. Está sempre presente. Tem que ter os hábitos, as reações que todos têm, ao contrário, o indivíduo não poderia ser um membro da comunidade. (...) A reação do Eu a uma atitude organizada transforma a mesma e assim, ocorre certa proporção de adaptação e readaptação. Esta reação do Eu pode ser um processo que envolve uma degradação do estado social, como uma integração superior.

Acrescenta, ainda, que o progresso social humano implica o emprego, por parte dos indivíduos, do seu mecanismo de consciência de si, socialmente surgido. Este pode ser usado tanto para produzir as transformações sociais progressivas, como para o desenvolvimento de si mesmos ou de suas personalidades individuais, como forma de se manter adaptativo a esse ritmo de reconstrução social.

Tais concepções apresentadas na teoria psicossociológica de Mead são consideradas, em seu conjunto, como a fonte principal da qual se derivaram as interpretações que deram origem ao interacionismo simbólico. Este que começou a se delinear entre os anos de 1930 e 1940, desenvolveu-se no transcurso das duas décadas seguintes e teve o seu nome cunhado em 1937 por Herbert Blumer, que estabeleceu os pressupostos da abordagem interacionista, por meio de seus escritos, cuja maioria se encontra reproduzida em sua mais importante publicação Symbolic Interactionism: perspective and method.

Para os interacionistas simbólicos o significado é um dos mais importantes elementos na compreensão do comportamento humano, das interações e dos processos. Os interacionistas argumentam que, para alcançar uma compreensão plena do processo social, o investigador precisa se apoderar dos significados que são experienciados pelos participantes em um contexto particular (JEON, 2004).

Sustentando-se nos preceitos teóricos de Mead, anteriormente expostos, Blumer (1969, p. 2) reafirma, abaixo, a noção de que o significado é um produto social, uma criação que emana das atividades dos indivíduos, à medida que estes interagem. Conforme esclarece em sua obra, a natureza do interacionismo simbólico tem como base a análise de três premissas:

A primeira é que o ser humano orienta seus atos em direção às coisas em função do que estas significam para ele (...). A segunda é que o significado destas coisas surge como consequência da 
interação social que cada qual mantém com seu próximo. A terceira é que os significados se manipulam e se modificam mediante um processo interpretativo desenvolvido pela pessoa ao defrontar-se com as coisas que vai encontrando em seu caminho.

Ao fundar-se nestas premissas, Blumer (1969) propõe o desenvolvimento de um esquema analítico da sociedade e da conduta humana. $\mathrm{O}$ tema central abordado são os processos de interação social ação social caracterizada por uma orientação imediatamente recíproca ao passo que o exame desses processos se baseia num conceito específico de interação que privilegia o caráter simbólico da ação social. O caso prototípico é o das relações sociais, em que a ação, ao invés de adotar a forma de mera transferência de regras fixas, é definida nas relações de forma recíproca e conjuntamente proposta e estabelecida. Assim, de acordo com Blumer (1969), as relações sociais são vistas como algo aberto e subordinado ao reconhecimento contínuo por parte dos membros da comunidade e não como algo estabelecido de uma vez por todas (JOAS, 1999).

De acordo com Haguette (1995), Blumer tenta ser fiel ao pensamento de Mead, abordando, sobretudo, a natureza da interação simbólica, da sociedade e da vida em grupo, dos objetos, da ação humana e da ação conjunta. Entretanto, aponta Haguette (1995), alguns autores consideram as noções de Blumer como uma interpretação errada das de Mead e outros alegam que as ideias centrais do interacionismo simbólico demonstram mais similaridade com as de outros pensadores do pragmatismo do que com as de Mead. Joas (1999), por exemplo, descreve a construção de Blumer como uma apropriação fragmentária do trabalho de Mead e, segundo Farr (1998), o interacionismo simbólico deve ser entendido como uma perspectiva teórica iniciada em Chicago por Blumer e baseada em "sua interpretação" de Mead.

Além disso, cumpre salientar que, não obstante o fato de Blumer (1969) ter sido, indubitavelmente, o mais influente entre os estudiosos a modelar o sentido da perspectiva interacionista simbólica, ele não foi o único a fazê-lo. As contribuições de Manford Kuhn também foram de vital importância para o delineamento de tal perspectiva (STRYKER; VRYAN, 2006). As diferentes concepções abraçadas por estes estudiosos, bem como as estratégias metodológicas por eles propostas são, a seguir, examinadas. 
Perspectivas conceituais e metodológicas das Escolas de Chicago E IoWA

As duas variantes mais proeminentes do interacionismo simbólico são representadas pelas Escolas de Chicago e Iowa associadas, respectivamente, às figuras de Herbert Blumer e Manford Kuhn. Os pressupostos básicos do interacionismo simbólico, elaborados por Blumer, são conhecidos como Interacionismo Clássico ou Interacionismo da Escola de Chicago. A Escola de Iowa, por outro lado, desenvolveu-se sob a orientação de Kuhn, o qual, fortemente influenciado pelo positivismo lógico, defendia uma abordagem mais estruturada para o interacionismo simbólico (BENZIES; ALLEN, 2001).

Observa-se, no geral, que ambas partem das concepções de Mead e convergem no tocante aos aspectos que integram a essência do interacionismo simbólico. Tais aspectos enfatizam que o mais característico e singular do comportamento humano é o fato de interagir mediante comunicações simbólicas, que requerem a definição da situação na qual se atua, assim como atuar assumindo e tendo em conta os comportamentos esperados pelos demais naquela situação. Os significados das ações podem ser mantidos, modificados ou dados pelos atores, os quais são assim, criadores ativos da vida social. Tudo isso estrutura na pessoa um self ou mediador entre esta e a organização social (BLANCO, 1988).

Quanto aos pontos de divergência entre estas duas escolas, cumpre analisar suas concepções. Tomando-se as ideias de Blumer, nota-se que seu entendimento é de que as pessoas constroem o próprio comportamento de forma ativa e contínua, durante o curso de sua interação. Para ele, essa incessante construção é uma característica de toda a vida social.

Assim, os significados, definições e interpretações, que são básicos para a interação social, passam por reformulações contínuas no curso das interações. Eles são emergentes e sujeitos à mudança de momento a momento e, portanto, não têm a generalização requerida pelos conceitos teóricos, em termos dos quais as teorias são desenvolvidas. Com base em tais concepções, conclui-se que os estudiosos podem alcançar uma compreensão do comportamento social após sua ocorrência, mas não é possível desenvolver explicações teóricas que visem a prever o comportamento social, seja individual, seja coletivo (STRYKER; VRYAN, 2006). 
No que tange ao desenvolvimento das pesquisas, Blumer (1969) também critica a metodologia convencional por utilizar meios de estabelecer a validade empírica de certos estudos por meio de esquemas, que ele julga inadequados para captar o caráter específico do objeto de estudo. Esse autor propõe, então, uma posição metodológica para o interacionismo simbólico, na qual defende a noção de que para compreender o mundo é necessário analisá-lo em termos das ações e interações de seus participantes. "Para a ciência empírica a 'realidade' só existe no mundo empírico, no qual se devem buscá-la e verificá-la" (BLUMER, 1969, p. 16).

Como esclarece Jeon (2004), a concepção de Blumer é de que o pesquisador deve ser capaz de interagir ativamente com as pessoas que estão sendo pesquisadas, de modo a ver as coisas do ponto de vista destas e no seu contexto natural. Por conseguinte, o autor entende que ao adotar a abordagem interacionista, o pesquisador precisa estar ativamente engajado no mundo em estudo e empreender uma análise de suas partes fundamentais, para o que ele propõe as técnicas de exploração e inspeção como métodos apropriados de pesquisa, conforme segue:

O estudo exploratório é o meio [...] para conseguir um conhecimento extenso e profundo da esfera da vida social e de desenvolver e acentuar a sua investigação. [...] Por seu caráter reflexivo, não está sujeito a nenhum conjunto de técnicas em particular, pode recorrer à observação direta, entrevistar pessoas, obter informações sobre a vida real, utilizar cartas e diários, consultar documentos públicos e organizar discussões de grupo. A finalidade da investigação exploratória é traçar um quadro em estudo, tão completo e preciso quanto permitem as condições vigentes [...]. A inspeção consiste em examinar o elemento analítico dado, considerando-o de diferentes ângulos, estabelecendo diversas perguntas e examinando novamente à luz das mesmas; em outras palavras, um exame detido e profundo [...]. A exploração e a inspeção representam a descrição e a análise e correspondem ao que se denomina investigação naturalista; um processo destinado a abordar o mundo empírico em seu caráter natural e contínuo, em lugar de se limitar a uma simulação do mesmo, uma abstração ou a sua substituição por uma imagem pré-estabelecida (BLUMER, 1969, p. 33).

Stryker e Vryan (2006) alertam para as implicações metodológicas derivadas de tais concepções, as quais, segundo os autores, envolvem as noções de que: 1) um método de pesquisa que não envolve exame direto do mundo empírico não pode gerar dados significativos e, portanto, 
carece de validade; 2) a manipulação matemática e estatística de dados quantitativos não tem valor para os estudos sociais, uma vez que tais dados são vazios de significados que constituem a essência do caráter do fenômeno sociológico; e, 3) as pesquisas não devem basear-se em uma teoria existente e dela derivarem hipóteses que antecipem resultados de comportamento social.

Além disso, enfatizam Stryker e Vryan (2006), os impactos da organização e das estruturas sociais sobre a ação social são minimizados na concepção de Blumer (1969).. Isto porque o seu entendimento é de que a busca por ligações entre o comportamento social e os elementos da estrutura (requisições de papel, expectativas, demandas situacionais, entre outros) é inconsistente com o reconhecimento de que o ser humano é uma criatura em constante definição e interpretação.

A visão de Manford Kuhn, por sua vez, contrasta frontalmente com a de Blumer, pois Kuhn aspirava a generalizações teóricas articuladas e rigorosamente testadas. Partindo do ponto de vista dos filósofos e sociólogos pragmatistas, que argumentavam que a estrutura social é criada, mantida e alterada por meio da interação simbólica, ele defendia que tal estrutura, uma vez criada, restringe novas interações. Assim baseando-se no ponto de vista de que o Self apresenta relativa estabilidade, Kuhn propõe instrumentos que permitiriam identificar e mensurar seus atributos. Para implantar este ponto de vista, ele adota uma concepção de estrutura social composta de redes de posições em relações estruturadas entre pessoas e de expectativas de papel associadas com tais posições (KUHN, 1964).

A proposta metodológica de Kuhn (1964) demanda o desenvolvimento de proposições gerais, cujas hipóteses específicas possam ser deduzidas e testadas. Se os testes corroboram as hipóteses, tem-se uma teoria útil para explicar e prever o comportamento em interação social. A construção de tais teorias deve ocorrer por meio de uma sólida mensuração dos conceitos incorporados nas proposições gerais do pesquisador, de forma que conceitos claros e precisos sejam necessários para mensurações confiáveis. Conforme esclarecem Stryker \& Vryan (2006), Kuhn não via contradição entre os conceitos vinculados ao interacionismo simbólico e o atendimento das exigências de uma mensuração científica confiável, bem como o desenvolvimento de teorias explicativas do comportamento social sujeitas ao teste empírico.

Observam-se, então, dois pontos centrais nas diferenças de abordagem entre as duas escolas. Um deles é a questão que envolve a natureza do comportamento humano em termos de liberdade ou 
determinação. Reconhecendo a tendência impulsiva e espontânea do "Eu" que inicia o ato, o qual termina em forma de "Mim", os seguidores da Escola de Chicago atribuem uma dimensão imprevisível e indeterminada ao comportamento (REYNOLDS; MELTZER, 1973). A perspectiva da Escola de Iowa, ao contrário, sustenta que o comportamento é, em parte, determinado pelas definições do ator, particularmente por seu Self, considerando que o "Eu" nem sempre é decisivo na interação (BLANCO, 1988). Assim, enquanto para Blumer prevalece a concepção, tanto do Self como da sociedade, mais dinâmica e orientada ao processo, continuamente renegociada em interação com outros; por outro lado, Kuhn entende que ambos representam estruturas cujos padrões são relativamente estáveis e previsíveis (HAGUETTE, 1995).

Blumer (1969) compreende a interação como um processo por meio do qual a vida grupal está em contínuo desenvolvimento, em permanente mudança e depende dos diferentes esquemas de interpretação de que utilizam os indivíduos participantes da mesma. Por outro lado, Kuhn enfatiza os aspectos mais estruturais na determinação da conduta, os quais dependem das definições sociais que são aprendidas sobre os objetos. Isto é, as atitudes em relação aos objetos do meio, positivas ou negativas, seriam uma consequência dos significados pelos quais as pessoas aprendem a designá-los.

Outro ponto de divergência fundamental entre estas duas escolas de pensamento situa-se no campo metodológico. Enquanto Blumer insistia na necessidade de uma metodologia distinta no estudo do homem, Kuhn enfatizava a comunalidade do método em todas as disciplinas científicas e acreditava na possibilidade de transformar os conceitos interacionistas em variáveis empregadas para testar proposições empíricas. Os métodos na Escola de Iowa incluíam desenhos quaseexperimentais, análises estatísticas, questionários, escalas, testes e procedimentos de laboratório - todos ligados a uma lógica de verificação. Os seguidores da Escola de Chicago, por sua vez, tendiam a adotar a observação participante, entrevistas, grupos focais e análise de documentos - todos ligados a uma lógica de descoberta (REYNOLDS; MELTZER, 1973).

Para Stryker e Vryan (2006), os elementos mais contrastantes das Escolas de Chicago e Iowa, aqui enfatizados, referem-se antes à história da perspectiva interacionista simbólica do que ao seu presente, reportamse mais aos polos extremos, característicos dos argumentos iniciais, do que às posições tomadas por interacionistas contemporâneos. Por esta razão, as classificações em relação às duas escolas são comumente utilizadas na literatura para descrever abordagens dentro do 
interacionismo simbólico, as quais, embora tenham bases históricas, representam posições extremas que não são usualmente adotadas pelos interacionistas.

\section{A PERSPECTIVA INTERACIONISTA SIMBÓLICA}

Enquanto historicamente as predileções metodológicas têm sido, talvez, de primeira importância para distinguir entre trabalhos realizados por estudiosos que abraçam a perspectiva interacionista simbólica, Stryker e Vryan (2006) apontam que isto parece se tornar menos importante com o passar do tempo. De fato, a diversidade de interesses daqueles que se identificam com a perspectiva contribuiu para o desenvolvimento de um número de variantes (FINE, 1993), não discutidas aqui por motivos de concisão, mas que sinalizam para as amplas possibilidades de aplicação dos pressupostos interacionistas.

Nesse sentido, Stryker e Vryan (2006) refletem que é possível encarar as diferentes possibilidades apresentadas por tais variantes como tensões que requerem uma escolha excludente; ou reconhecer os benefícios que derivam das diferentes variantes dentro de uma perspectiva interacionista mais ampla. Esclarecem, ainda, as vantagens desta última posição que, segundo os autores, vem sendo adotada por boa parte dos interacionistas simbólicos contemporâneos.

Entretanto, apesar de que as ideias do interacionismo simbólico não requeiram um comprometimento com estratégias qualitativas de pesquisa, tal perspectiva teórica tem sido quase que exclusivamente associada à utilização de métodos tais como a etnografia, observação participante e entrevistas intensivas não estruturadas, entre outras; quando é aceita a utilidade de uma variedade maior de métodos nas ciências sociais (BENZIES; ALLEN, 2001).

Quanto aos aspectos conceituais, referentes às questões de estabilidade ou mudança, construção social ou reprodução, criatividade ou conformidade, Stryker e Vryan (2006) ponderam que não são mutuamente excludentes, mas constituem características observáveis da vida social. Dessa forma, embora o comportamento humano carregue um elemento de imprevisibilidade, conserva também certa continuidade, dado que não se pode ignorar o fato de que o mesmo é constrangido pela estrutura social em que se encontra inserido.

Com base nesse entendimento e na posição de se trabalhar dentro de uma perspectiva interacionista simbólica mais ampla, conceitos generalizados podem ser potencialmente úteis, teorias podem ser 
formuladas e testadas e trabalhos utilizando métodos qualitativos ou quantitativos podem ser estratégicos para os pesquisadores. E ainda, considerando-se que um método não pode se adequar a todos os problemas de pesquisa, a adesão absoluta a preferências metodológicas de qualquer tipo limitaria o leque de problemas que podem ser abordados por meio das lentes da referida perspectiva. Dessa forma, o interacionismo simbólico, que tem uma extensa tradição no estudo da organização social e dos processos sociais (HALL, 1987), continua oferecendo possibilidades de contribuição em diversos campos de estudo.

Todavia, a despeito das inúmeras potencialidades relacionadas a esta perspectiva teórica, importa mencionar que, ao longo dos anos, a mesma também foi alvo de críticas, que se multiplicaram especialmente durante a década de 1970. Meltzer, Petras e Reynolds (1975), por exemplo, apontaram a minimização da estrutura social como a principal fragilidade do interacionismo simbólico, a qual estaria relacionada a uma subvalorização da estratificação social, assim como da distribuição desigual de riqueza e poder.

Nessa vertente seguiram os demais críticos (WORSLEY, 1973; COSER 1975; entre outros) ao entender o interacionismo simbólico como uma perspectiva limitada por sua restrição aos "micro" aspectos da organização social, que, como tal, seria incapaz de abordar adequadamente os "macro" fenômenos, tais como estrutura social, padrões de desigualdade e poder. De acordo com Joas (1999, p. 131), tais críticas que tomam a perspectiva interacionista simbólica como limitada a fenômenos de imediaticidade interpessoal, atribuem-lhe "a visão de que o complexo das relações macrossociais não ultrapassa o horizonte da sociabilidade mundana".

Refutando, entretanto, a noção de que o interacionismo simbólico nega ou exclui a existência de fenômenos como classes sociais, instituições sociais, estruturas de poder e estratificação social, alguns estudiosos (MAINES, 1977; DENNIS; MARTIN, 2005; SAUDER, 2005, entre outros) alegam que este não ignora as considerações acerca da estrutura social. Ademais, esses consideram que não há nada inerente a tal perspectiva teórica que impeça a análise da organização e estrutura sociais.

No que tange ao estudo da estratificação social, por exemplo, Sauder (2005) argumenta que, ao examinar cuidadosamente como o status tende a ser indicado, empregado, mantido ou alterado ao longo do tempo, a abordagem interacionista simbólica proporciona uma explicação de como este afeta tanto o comportamento individual quanto o social. Com 
base nestas noções, Sauder (2005) propõe um modelo para o estudo do status com base nesta perspectiva.

Ainda, considerando as relações de poder, Dennis e Martin (2005) sugerem que os estudos interacionistas têm contribuído para a compreensão dos processos sociais, por intermédio dos quais, nas situações cotidianas, o poder é desempenhado e institucionalizado. Desta forma, tais estudos estariam propiciando explicações acerca dos meios pelos quais os padrões culturais e restrições institucionais exercem influência sobre os indivíduos.

Corroborando Maines (1977), estes autores buscam demonstrar que uma abordagem interacionista simbólica não descarta as restrições que organizações e estruturas sociais impõem aos atores individuais. Ao contrário, examina estas estruturas, insistindo que os processos de restrição e/ou coação são compostos e expressos por meio de interações individuais.

As ideias centrais do interacionismo simbólico são de que, individualmente e coletivamente, os seres humanos são ativos, criativos e não somente respondentes às forças do ambiente externo. Os ambientes nos quais eles agem e com os quais interagem são simbólicos; os símbolos designados aos ambientes são produzidos em interação e podem ser manipulados no curso da interação; o pensamento pode ser usado para antecipar a efetividade de alternativas de ação planejadas para resolver problemas e a escolha entre cursos de ação alternativos é uma característica da conduta social (STRYKER; VRYAN, 2006). Dessa forma, à medida que o interacionismo simbólico constitui-se em uma perspectiva teórica que pode facilitar uma melhor compreensão, tanto das relações entre indivíduos, quanto entre estes e as estruturas sociais, identifica-se um significativo potencial de aplicabilidade de seus pressupostos básicos na condução de estudos organizacionais.

\section{O INTERACIONISMO SIMBÓLICO E OS ESTUDOS ORGANIZACIONAIS}

Como enfatiza Morgan (1983), diferentes pressupostos dão lugar a diferentes bases para o conhecimento sobre o mundo social. As imagens de um fenômeno social, que ele aponta como usualmente expressas em termos de metáforas, proporcionam um meio de se estruturar uma investigação científica e favorecem dadas estâncias epistemológicas particulares. Estas, por sua vez, geram conceitos e métodos específicos por meio dos quais é possível obter o conhecimento de dado fenômeno. 
Assim, as metodologias ligam o pesquisador à situação a ser estudada em termos de regras, procedimentos e protocolos gerais que operacionalizam o conjunto de pressupostos básicos presentes na estância epistemológica adotada pelo pesquisador. Como existem várias abordagens metodológicas disponíveis para investigar diferentes pontos de vista metafóricos, torna-se relevante ter uma clara compreensão das conexões entre perspectiva teórica e método (MORGAN, 1980).

Partindo de tais considerações, tem-se que a escolha pela estância interacionista simbólica como perspectiva teórica a guiar a condução de estudos organizacionais deve ser baseada em pressupostos que precisam estar claros para o pesquisador. Ao estudar o comportamento humano, considerando sua interação mediante comunicações simbólicas, em que os significados das ações podem ser mantidos, modificados ou dados pelos atores, cujo self atua como mediador entre estes e a organização social (BLANCO, 1988), o interacionismo simbólico representa um potencial para compreensão de diferentes aspectos da vida organizacional, complementando outras perspectivas teóricas normalmente utilizadas neste campo de estudos. Num esforço de exemplificar suas potencialidades, busca-se elucidar alguns temas em estudos organizacionais beneficiados pela abordagem interacionista simbólica e tecer algumas considerações acerca dos aspectos metodológicos relacionados à operacionalização de seus pressupostos básicos.

\section{Perspectivas temáticas em estudos organizacionais}

Considerando-se a complexidade e a pluralidade que são típicas da vida organizacional, evidencia-se que a utilização de uma perspectiva interacionista simbólica em estudos organizacionais apresenta uma variedade de possibilidades. Nessa perspectiva podem ser exploradas, não somente as ambiguidades e contradições, mas também os vários modos de representações, os múltiplos valores e a construção das significações da vida organizacional, pelos atores envolvidos. Apresentam-se, a seguir, algumas temáticas nesse campo de estudos que têm sido abordadas sob a perspectiva interacionista simbólica, cujas possibilidades de contribuição seguem propiciando oportunidades ao desenvolvimento de novas pesquisas.

Entre estas, encontra-se o estudo da linguagem nas organizações. Cossette (1998) identifica a possibilidade de que a perspectiva interacionista simbólica possa contribuir no sentido de compreender os significados atribuídos e a construção da linguagem no contexto da situação interativa em que esta ocorre. Dessa forma, o autor propõe um 
modelo para o estudo da linguagem nas organizações e discute que, baseado na perspectiva proposta, pode se abordar, por exemplo, a extensão e o modo como a linguagem do gestor e do empregado são determinadas por fatores específicos da situação interativa e, principalmente, como o significado atribuído à linguagem é determinado pela percepção de cada um deles a respeito das intenções do outro. De forma geral, entende-se que a estância interacionista simbólica no estudo da linguagem pode produzir a melhor compreensão acerca da dinâmica organizacional. Isto se torna relevante dado que, conforme sugere Cossette (1998), se a linguagem é modelada pela estrutura em que é produzida, também contribui para modelar a mesma.

$\mathrm{O}$ interacionismo simbólico é também uma abordagem importante para o estudo e compreensão da cultura organizacional. Conforme Morgan (1996), falar sobre cultura refere-se ao processo de construção da realidade que permite às pessoas ver e compreender eventos, ações, objetos, expressões e situações particulares de maneiras distintas. A construção e a manutenção da cultura pressupõem que existe um determinado nível de compartilhamento da realidade social edificada pelos membros de um grupo (BERGER; LUCKMAN, 1967/1985). Numerosas estruturas organizacionais e práticas incorporam padrões de significado subjetivo que são cruciais para o entendimento de como funciona a organização no dia a dia. Nesse sentido, Silva e Zanelli (2004) salientam que a perspectiva interacionista simbólica no estudo da cultura organizacional torna-se relevante, uma vez que enfatiza a recuperação do processo de elaboração do universo simbólico ou da construção da realidade de determinada organização social.

Estreitamente relacionado ao estudo da cultura, o tema da socialização organizacional, o qual pode ser considerado como um dos aspectos essenciais de preservação ou mudança da cultura organizacional, também vem recebendo influência significativa da corrente do interacionismo simbólico. Com base nos pressupostos interacionistas, de que os indivíduos contribuem para os significados que surgem em dado contexto social, os estudos em socialização organizacional passaram a considerar o papel ativo dos iniciantes nesse processo, considerando que atuam, ao mesmo tempo, como sujeito e objeto. Nas palavras de Borges e Albuquerque (2004, p. 332), a compreensão do processo de socialização organizacional, na perspectiva interacionista simbólica, é de que "não há um espaço ilimitado de deliberação do sujeito, nem o indivíduo é um mero produto do meio e, sim, fruto dessa dinâmica". De acordo com essa visão, a realidade e o significado seriam construções sociais (BERGER; 
LUCKMANN, 1967/1985) e, com base na mesma, busca-se compreender a maneira como são construídas as atitudes, comportamentos e conhecimentos necessários para que o iniciante possa participar como um membro da organização.

Ainda, com respeito ao estudo do status nas organizações, alguns estudiosos (PODOLNY, 1993; BENJAMIN; PODOLNY, 1999) têm evidenciado como as questões relacionadas a este tema desempenham um papel central nos processos organizacionais. Conforme Sauder (2005), uma perspectiva interacionista oferece um meio de examinar como as reputações que definem o status são construídas e institucionalizadas, como mudam ao longo do tempo e como afetam as interações entre a organização e seus membros. Pode, ainda, auxiliar a compreensão acerca dos meios pelos quais os atores simbolizam o status, os processos por meio dos quais esses símbolos são usados para criar e manter as respectivas posições e a relação entre o status de uma organização e o status de seus membros constituintes.

Cumpre considerar, ainda, as possibilidades de aplicação da perspectiva interacionista simbólica no estudo dos processos de aprendizagem organizacional, das questões relativas às percepções, atitudes, crenças e valores construídos no ambiente de trabalho e também da identidade e simbolismo nas organizações. Além das possibilidades de contribuição derivadas da aplicação dos pressupostos interacionistas simbólicos aos estudos organizacionais, ilustradas aqui por meio dos exemplos apresentados, há que se considerar outro elemento relevante, que diz respeito aos aspectos metodológicos de tais estudos.

\section{Perspectivas metodológicas em estudos organizacionais}

Uma vez que as metodologias ligam o pesquisador à situação a ser estudada, operacionalizando o conjunto de pressupostos básicos presentes na estância epistemológica adotada (MORGAN, 1980), torna-se relevante tecer algumas considerações acerca das possibilidades metodológicas, que se configuram para os estudos conduzidos à luz do interacionismo simbólico.

Nesse sentido, importa salientar que o interacionismo simbólico, embora conhecido e discutido como uma perspectiva teórica adequada à condução de investigações qualitativas tem seus pressupostos também compatíveis com métodos quantitativos (MELTZER; PETRAS; REYNOLDS, 1975). Isto o torna uma estância epistemológica que proporciona não somente a maior flexibilidade na escolha do método, 
como também a adequação ao desenho de pesquisas que se caracterizem pela adoção de múltiplos métodos.

Embora exista reconhecimento de que não há dicotomias entre métodos quantitativos e qualitativos de pesquisa, porquanto a realidade, em sua complexidade, exige a ambos, persiste a noção de que métodos qualitativos são concessivos e não podem disputar espaço com os quantitativos. Muitas vezes, tal discussão é atrapalhada pelo próprio abuso dos métodos qualitativos (DEMO, 2001); "o que não elide sua necessidade por razão epistemológica precípua: a tamanha complexidade da realidade [...], que não é devassável apenas quantitativamente" (DEMO, 2005, p. 80).

Dados e análises qualitativas têm, não somente a virtude de proporcionar informações ricas e em profundidade, quanto a compreensão de situações que podem facilitar a geração de teorias, particularmente com respeito a novas questões ou àquelas sobre as quais pouco se sabe. Além disso, alguns aspectos da vida social, de interesse dos estudos organizacionais, podem não ser acessíveis por meio de questionários estruturados e outras formas não naturalistas de coleta de dados, ou podem não ser apropriados à quantificação.

Ao mesmo tempo, dados qualitativos estão em desvantagem, comparados aos quantitativos, quando o interesse está em testar a generalidade de um argumento teórico. Além disso, levantamentos em maior escala permitem a avaliação de modelos multivariados, envolvendo conjuntos complexos de dados, baseados em amostras relativamente representativas.

Nessa vertente, importa salientar a relevância de uma integração de metodologias qualitativas e quantitativas nos estudos organizacionais, dado que a combinação de métodos, além de contribuir para aumentar a profundidade e a amplitude de conhecimento acerca de dado fenômeno, pode compensar os vieses inerentes a cada método (BENZIES; ALLEN, 2001). Por essa razão, alguns interacionistas têm começado a incorporar múltiplos métodos em seu trabalho, obtendo as contribuições únicas de cada um deles (STRYKER; VRYAN, 2006). Pela mesma razão, entendese que essa pode ser uma estratégia potencialmente útil quando da adoção de uma perspectiva interacionista simbólica nos estudos organizacionais.

Como enfatizam Stryker e Vryan (2006), uma vez que o desenvolvimento de teorias envolve a exploração e a formulação de proposições, que são construídas em esquemas teóricos, para então serem inspecionadas e testadas por meio de validação no mundo empírico; desenhos de pesquisa que façam uso de múltiplos métodos, dentro da 
perspectiva interacionista simbólica, também podem permitir ao pesquisador tanto formular quanto validar teorias, o que também se aplica ao campo de estudo das organizações.

Cumpre considerar, por fim, que na escolha do método entram tanto a preferência do pesquisador, quanto a avaliação da adequação do método e das possibilidades de pesquisa, que variam em conformidade com os objetivos estabelecidos. Tais aspectos deverão embasar a opção pela adoção de análises qualitativas ou pela combinação de diferentes estratégias metodológicas na operacionalização dos pressupostos interacionistas, aplicados aos estudos organizacionais. Ademais, não devem ser subestimados os desafios implicados tanto na condução de pesquisas qualitativas, quanto na adoção de múltiplos métodos, haja vista o tempo e domínio técnico requeridos à aplicação de ambas as estratégias.

\section{REFLEXões FinAIS}

O presente ensaio teve como intuito apresentar uma revisão acerca da abordagem interacionista simbólica, resgatando suas origens, pressupostos básicos e possibilidades de contribuição aos estudos organizacionais. Embora, não tenham sido esgotados neste trabalho todos os desdobramentos de tal perspectiva teórica, foi possível observar, no cerne das discussões, que o interacionismo simbólico, em sua trajetória, tem se constituído como objeto de reflexão de vários estudiosos; seja pelo reconhecimento de suas possibilidades de aplicação, ou pela elucidação de suas limitações. A despeito das críticas e de sua secundarização, juntamente com outras tendências sociológicas, por um longo período (ÁLVARO; GARRIDO, 2003), o interacionismo simbólico evoluiu e se fortaleceu. Na compreensão de Blanco (1988), isso talvez se explique pelo fato de os pressupostos teóricos defendidos pelos interacionistas simbólicos conduzirem a atenção para uma temática ampla, com aplicações em diversos campos de estudo.

Tal fortalecimento deve ser, contudo, compreendido tanto no contexto de sua evolução conceitual e de abrangência, notadamente no que se refere a abarcar melhor a dialética que articula aspectos estruturais da sociedade e construção do sujeito singular, quanto no contexto do desenvolvimento das ciências humanas e sociais (ÁLVARO; GARRIDO, 2003). Desta forma, o entendimento aqui é que o interacionismo simbólico se fortaleceu num caminho que permite abordar os fenômenos, aplicando uma dialética entre aspectos da estruturação social e a construção das individualidades, entre o geral e o particular, entre o 
cultural e o singular, entre sujeito e objeto; apreendendo as contradições da vida contemporânea no contexto de sociedades plurais, bem como refletindo sobre os fenômenos sociopsicológicos, sem ignorar o caráter histórico dos mesmos.

Com base nestas considerações, é possível defender que o interacionismo simbólico representa uma alternativa, a um só tempo viável e sólida, para aprofundar a compreensão da realidade organizacional. Dessa forma, buscou-se evidenciar as possibilidades que se descortinam mediante a utilização de tal perspectiva nos estudos organizacionais, citando como exemplos, suas contribuições e potencialidades no desenvolvimento de estudos da linguagem, da cultura, da socialização e do status nas organizações. Sabe-se que tais exemplos não cobrem todos os temas que são e podem ser beneficiados pela adoção de uma abordagem interacionista simbólica nos estudos organizacionais; mas, espera-se que tenham podido ilustrar o potencial que representa para compreensão de diferentes aspectos da vida organizacional, complementando outras perspectivas teóricas normalmente utilizadas neste campo de estudos.

Foram tecidas, ainda, algumas considerações acerca dos aspectos metodológicos das pesquisas em organizações, desenvolvidas à luz do interacionismo simbólico, o qual, embora seja conhecido e discutido como uma perspectiva teórica adequada à condução de investigações qualitativas, tem seus pressupostos também compatíveis com métodos quantitativos. Entende-se que, ao oportunizar a adoção de abordagens qualitativas e quantitativas, facilitando inclusive a conjugação de múltiplos métodos de pesquisa, o interacionismo simbólico oferece a possibilidade de uma compreensão mais rica e completa das questões organizacionais. Nessa vertente, enfatizam-se os benefícios advindos de uma integração de métodos qualitativos e quantitativos, considerando-se que contribui não apenas para maior profundidade e amplitude de conhecimento acerca de dado fenômeno, como também para compensar os vieses inerentes a cada método (BENZIES; ALLEN, 2001).

Por fim, é importante salientar que a adoção do interacionismo simbólico como perspectiva teórica não resolve todos os problemas relacionados à escolha e utilização de métodos nas pesquisas. Não se defende tampouco, a primazia de dada estratégia metodológica em relação a outras, visto que, baseado nos objetivos do estudo, o pesquisador deve tomar uma decisão sobre a prioridade e a sequência dos métodos. Além disso, qualquer perspectiva teórica tem seu viés e é limitada por natureza. Enquanto o interacionismo simbólico sensibiliza os 
pesquisadores para certas pressuposições, ele não poderá revelar completamente tudo o que há para saber a respeito das questões organizacionais. Para uma utilização adequada do mesmo, os pesquisadores devem estar conscientes de suas limitações.

\section{REFERÊNCIAS}

ÁLVARO, J. R.; GARRIDO, A. Psicologia social: perspectivas psicológicas y sociológicas. Madri: McGraw Hill, 2003.

ALVARO, J. L.; GARRIDO, A.; SCHWEIGER, I.; TORREGROSA, J. R. Introducción a la psicología social sociológica. Barcelona: Editorial UOC, 2007.

BENJAMIN, B. A.; PODOLNY, J. M. Status, quality, and social order in the California wine industry. Administrative Science Quarterly, v. 44, n. 3, p. 563-589, 1999.

BENZIES, K. M.; ALLEN, M. N. Symbolic interactionism as a theoretical perspective for multiple method research. Journal of Advanced Nursing, v. 33, n. 4, p. 541- 547, 2001.

BERGER, P. L.; LUCKMANN, T. (1976). A construção social da realidade. Petrópolis: Vozes, 1985.

BLANCO, A. Cinco tradiciones en la psicología social. Madrid:

Ediciones Morata, 1988.

BLUMER, H. El interaccionismo simbolico: perspectiva y metodo. Barcelona: Hora, 1969.

BORGES, L. O.; ALBUQUERQUE, F. J. B. Socialização organizacional. In: ZANELLI, J. C.; BORGES-ANDRADE, J. E. ; BASTOS, A. V. B. (Orgs.). Psicologia, organizações e trabalho no Brasil. Porto Alegre: Artmed, 2004.

COSER, L. Presidential address: two methods in search of a substance. American Sociological Review, v. 40, n. 6, p. 691-700, 1975.

COSSETTE, P. The study of language in organizations: a symbolic interactionist stance. Human Relations, v. 51, n. 11, p. 1355-1377, 1998.

COULON, A. A Escola de Chicago. Campinas: Papirus, 1995.

DEMO, P. Pesquisa e informação qualitativa. Campinas: Papirus, 2001. 
DEMO, P. Teoria - para quê? Revista Eletrônica de Gestão Organizacional, v. 3, n. 2, p. 74-79, 2005.

DENNIS, A.; MARTIN, P. J. Symbolic interactionism and the concept of power. The British Journal of Sociology, v. 56, n. 2, p. 191-213, 2005.

FARR, R. M. As raízes da psicologia social moderna. Petrópolis: Vozes, 1998.

FINE, G.A. The sad demise, mysterious disappearance and glorious triumph of symbolic interactionism. Annual Review of Sociology, v. 19, $\mathrm{n}$. 1, p. 61-87, 1993.

HAGUETTE, T. M. F. Metodologias qualitativas na sociologia. 4. ed. Petrópolis: Vozes, 1995.

HALL, P. M. Interactionism and the study of social organization. The Sociological Quarterly, v. 28, n. 1, p.1-22, 1987.

JEON, Y. The application of grounded theory and symbolic interactionism. Scandinavian Journal of Caring Sciences, v. 18, n. 2, p. 249-256, 2004.

JOAS, H. Interacionismo simbólico. In: GUIDDENS, A.; TURNER, J. Teoria social hoje. São Paulo: Unesp, 1999.

KANTER, R. M.. Symbolic interactionism and politics in systemic perspective. Sociological Inquiry, v. 42, n. 3, p. 77-92, 1972.

KUHN, M. H. Major trends in symbolic interaction theory in the past twenty-five years. Sociological Quarterly, v. 5, n. 1, p. 61-84, 1964.

MAINES, D. R. Social organization and social structure in symbolic interactionist thought. Annual Review of Sociology, v. 3, n. 2, p. 235-259, 1977.

MEAD, G. H. Espiritu, persona y sociedad: desde el punto de vista del condutismo social. Barcelona: Paidos, 1934.

MELTZER, B. N.; PETRAS, J. W.; REYNOLDS, L. T. Symbolic interactionism: genesis, varieties and criticism. London: Routledge and Kegan Paul, 1975.

MORGAN, G. Paradigms, metaphors and puzzle solving in organization theory. Administrative Science Quarterly, v. 25, p.605-622, 1980.

MORGAN, G. Beyond method: strategies for social research. Califórnia: Sage, 1983. 
MORGAN, G. Imagens da Organização. São Paulo: Atlas, 1996.

PODOLNY, J. M. A status-based model of market competition. American Journal of Sociology, v. 98, n. 3, p. 829-72, 1993.

PORTUGAL, F. T. Psicologia Social em George Mead, na Escola de Chicago e em Erving Goffman. In: JACÓ-VILELA, A.; FERREIRA, A. A.; PORTUGAL, F. T. (Orgs.). História da Psicologia. Rio de Janeiro: NAU Editora, 2006.

REYNOLDS, L. T.; MELTZER, B. N. The origins of divergent methodological stances in symbolic interactionism. The Sociological Quarterly, v.14, n. 2, p.189-199, 1973.

SAUDER, M. Symbols and contexts: an interactionist approach to the study of social status. The Sociological Quarterly, v. 46, n. 2, p. 279-298, 2005.

SILVA, N.; ZANELLI, J. C. Cultura organizacional. In: ZANELLI, J. C.; BORGES-ANDRADE, J. E.; BASTOS, A. V. B. (Orgs.). Psicologia, organizações e trabalho no Brasil. Porto Alegre: Artmed, 2004.

STRYKER, S.; VRYAN, K. D. The symbolic interactionist frame. In: DELAMATER, J. (Org.). Handbook of social psychology. New York: Springer, 2006.

TREZZA, M. C. S. F. Construindo através da doença possibilidades de sua libertação para uma outra forma de viver: um modelo teórico representativo da experiência de pessoas que tiveram câncer. Tese (Doutorado em Enfermagem). Universidade Federal do Rio de Janeiro, Rio de Janeiro, RJ, 2002.

WORSLEY, P. The state of theory and the status of theory. Sociology, v. 8, n. 1, p. 1-17, 1973.

\footnotetext{
${ }^{1}$ A tese central do pragmatismo é de que a verdade de uma ideia deriva de suas consequências práticas. Deste modo, a verdade é entendida não como uma propriedade essencial das coisas, mas como uma possibilidade cuja efetividade irá depender de seus efeitos sobre a conduta. Nesta perspectiva, uma crença ou ideia será verdadeira se puder servir de guia às ações dos indivíduos (ÁLVARO; GARRIDO, 2003).
} 
DAdOS DOS AUTORES

VIRGínia Donizete de CARVALHo (vircah@gmail.com)

Doutora em Psicologia Social pela UFRN

Instituição de vinculação: Universidade Federal de Alfenas

Varginha/MG - Brasil

Áreas de interesse em pesquisa: Cultura, valores e organizações, Fatores humanos no trabalho.

Recebido em: 03/09/2011 • Aprovado em: 14/12/2011 